Lipophilic conjugates for carrier-free delivery of RNA importable into human mitochondria

Ilya Dovydenko ${ }^{1,3}$, Mariya Meschaninova ${ }^{2}$, Anne-Marie Heckel ${ }^{1}$, Ivan Tarassov $^{1}$, Alya Venyaminova $^{2}$ and Nina Entelis ${ }^{1}$ *

${ }^{1}$ UMR 7156 GMGM University of Strasbourg - CNRS, Strasbourg, France

${ }^{2}$ Laboratory of RNA Chemistry, Institute of Chemical Biology and Fundamental Medicine SB RAS, Novosibirsk, Russia

${ }^{3}$ Laboratory of Synthetic Biology, Institute of Chemical Biology and Fundamental Medicine SB RAS, Novosibirsk, Russia

* corresponding author : UMR 7156 Université de Strasbourg-CNRS, 4, Allée Konrad Roengen, 67000 Strasbourg, France

Tel (+33) 368851481

E-mail: $\underline{\text { n.entelis@ unistra.fr }}$

Running title: Synthesis of lipophilic conjugates 


\title{
Lipophilic conjugates for carrier-free delivery of RNA importable into human mitochondria
}

\author{
Ilya Dovydenko ${ }^{1,3}$, Mariya Meschaninova ${ }^{2}$, Anne-Marie Heckel $^{1}$, Ivan Tarassov ${ }^{1}$, Alya \\ Venyaminova $^{2}$ and Nina Entelis ${ }^{1}$ *
}

\section{Summary}

Defects in human mitochondrial genome can cause a wide range of clinical disorders which still do not have efficient therapies. The natural pathway of small non-coding RNA import can be exploited to address into mitochondria therapeutic RNAs. To create an approach of carrier-free targeting of RNA into living human cells, we designed conjugates containing a cholesterol residue and developed the protocols of chemical synthesis of oligoribonucleotides conjugated with cholesterol residue through cleavable $\mathrm{pH}$-triggered hydrazone bond. The biodegradable conjugates of importable RNA with cholesterol can be internalized by cells in a carrier-free manner; RNA can then be released in the late endosomes due to a change in $\mathrm{pH}$ and partially targeted into mitochondria. Here we provide detailed protocols for solid-phase and "in solution" chemical synthesis of oligoribonucleotides conjugated to a cholesterol residue through a hydrazone bond. We describe the optimization of the carrier-free cell transfection with these conjugated RNA molecules and methods for evaluating the cellular and mitochondrial uptake of lipophilic conjugates.

Key Words: RNA therapeutics; carrier-free cell delivery; synthesis of lipophilic conjugates; mammalian cells transfection; fluorescent microscopy. 


\section{Introduction}

Mitochondria harbour their own genetic system, but critically depend on the import of nuclearencoded macromolecules. In all eukaryotes, selected non-coding RNAs (including tRNAs, miRNAs and lncRNAs) produced from the nuclear genome are partially redirected into the mitochondria, where they participate in gene expression (reviewed in (1)).

Defects in human mitochondrial genome can cause a wide range of clinical disorders, mainly neuromuscular diseases (2). Since the most of these diseases still do not have efficient therapies, gene therapy (or more precisely termed, "nucleic acid exploiting therapy") represents an open possibility. The problem is that there are no methods of the directed transport of DNA or mRNA molecules into the mitochondria, since these organelles are surrounded by a double membrane bearing a negative charge.

The natural pathway of small non-coding RNA import can be exploited to address into mitochondria therapeutic RNAs. Our studies of the import of small non-coding RNAs into human mitochondria allowed the identification of short RNA structural domains serving as import determinants. RNA molecules containing these domains can penetrate into human mitochondria (3-5). This finding has been used to target to mitochondria various small non-coding RNAs, including antireplicative and guide RNAs. The antireplicative strategy aims to prevent the replication of mutant mtDNA by designed recombinant RNA that can be imported and annealed in the replication fork (6). We have demonstrated that small RNAs containing structural determinants for mitochondrial import and 20-nucleotide sequence corresponding to the mutated region of mtDNA, are able to anneal selectively to the mutated mitochondrial genomes. Capable to penetrate into mitochondria of cultured human cells, these RNAs induced a decrease of the proportion of mtDNA bearing pathogenic mutations $(\mathbf{5 , 4 , 6 )}$. We also designed guide RNAs (a component of CRISPR/Cas9 system) targeting different regions of mtDNA and able to be targeted to human mitochondria (7). 
A factor that significantly limits biomedical application of RNAs is their inefficient delivery to target cells and tissues (8) due to their large size, negative charge and low stability. Many various systems, including lipid nanoparticles or RNA modifications have been developed to overcome these obstacles (9-12). The successful system for nucleic acids delivery should meet a number of requirements: low cytotoxicity, resistance to nuclease degradation, possibility of endosomal escape and capability of entering the appropriate cellular compartment $(\mathbf{1 3 , 1 4})$. One of the ways to create successful delivery systems is bioconjugation. Currently, for the synthesis of bioconjugates of oligonucleotides with ligands of different functionality, there are two main synthetic strategies - conjugation "in solution" and on solid-phase. Each of these approaches has its own advantages and disadvantages (e.g. see $(15,16))$. Both strategies allow the use of various types of stable or labile linkers for covalent bioconjugation $(\mathbf{1 7 , 1 8 )}$.

To decrease the toxicity of the commonly used cell transfection procedure (RNA delivery in the complexes with commercial cationic lipids) and to create an approach of carrier-free targeting of various RNAs into living human cells, we designed conjugates containing a cholesterol residue. Because cholesterol could stall the mitochondrial import of therapeutic RNA due to attachment to the mitochondrial membranes, we developed the protocols of chemical synthesis of oligoribonucleotides conjugated with cholesterol residue through cleavable hydrazone bond $(19,20)$. To obtain an optimal balance between this bond's lability under acidic conditions and stability under neutral conditions, we used the combination of an aromatic aldehyde with an aliphatic acyl hydrazide (21). We designed a linker containing 2 carbon atoms, hydrazone bridge and another 6 carbon atoms between 5'-nucleotide of RNA and cholesterol residue (Fig. 1). Conjugates containing $\mathrm{pH}$-triggered hydrazone bond were characterized by efficient carrier-free cellular uptake and partial co-localization with mitochondrial network. Moreover, the imported oligoribonucleotide designed to target a pathogenic point mutation in mitochondrial DNA was able to induce a decrease in the proportion of mutant mitochondrial genomes (19). 
The rationale of the methodology is to use the non-toxic cholesterol ligand to permit the conjugated RNA molecule to enter into the cell without additional formulation via endocytosis pathway, followed by a pH-dependent cleavage of the hydrazone bond in the late endosomes and release of the active cholesterol-free RNA, which then can be targeted into mitochondria and affect the replication of the mutant mtDNA (Fig.1).

Here we provide detailed protocols of the solid-phase and "in solution" chemical synthesis of oligoribonucleotides conjugated to a cholesterol residue through cleavable $\mathrm{pH}$-triggered hydrazone bond, and the optimization of cultured cells transfection with these conjugated molecules.

\section{Materials}

\subsection{Synthesis of hydrazide of 6-(cholesteryloxycarbonylamino)hexanoic acid} (see Note 1)

1. Pyridine $(\mathrm{Py})$, water $\left(\mathrm{H}_{2} \mathrm{O}\right)<0.01 \%$.

2. 6-Aminohexanoic acid, $\geq 98.5 \%$.

3. Chlorotrimethylsilane, $\geq 98.0 \%$.

4. Cholesteryl chloroformate, $95 \%$.

5. Dichloromethane $\left(\mathrm{CH}_{2} \mathrm{Cl}_{2}\right), \geq 99.8 \%, \sim 20 \mathrm{ppm}$ amylene as stabilizer, water $\left(\mathrm{H}_{2} \mathrm{O}\right)<0.02 \%$.

6. Hydrochloric acid (HCl), 36.5-38.0\%.

7. Sodium chloride $(\mathrm{NaCl}), \geq 99.0 \%$.

8. Sodium sulfate $\left(\mathrm{Na}_{2} \mathrm{SO}_{4}\right), \geq 99.0 \%$, anhydrous, granular.

9. Ethanol, 94-96\%.

10. Phosphorus trichloride $\left(\mathrm{PCl}_{3}\right), 99 \%$.

11. Methanol $\left(\mathrm{CH}_{3} \mathrm{OH}\right), \geq 99.9 \%$.

12. Sodium bicarbonate $\left(\mathrm{NaHCO}_{3}\right), \geq 95.0 \%$.

13. Hydrazine monohydrate $\left(\mathrm{NH}_{2} \mathrm{NH}_{2} \cdot \mathrm{H}_{2} \mathrm{O}\right)$. 
14. Kieselgel $\mathrm{F}_{254}$ thin-layer chromatography plate.

15. Silica gel, pore size $60 \AA$ A, 230-400 mesh.

16. Rotary evaporator system, Rotavapor R-200.

17. Standard organic laboratory glassware.

18. UV lamp (254 nm).

19. Bruker AVANCE III 400 NMR-spectrometer.

\subsection{Synthesis of oligoribonucleotides and their aldehyde-modified analogs}

1. Acetonitrile $(\mathrm{AcN})$, water $\left(\mathrm{H}_{2} \mathrm{O}\right)<0.02 \%$.

2. Tetrahydrofuran (THF), 300 ppm butylhydroxytoluene as inhibitor, water $\left(\mathrm{H}_{2} \mathrm{O}\right)<0.02 \%$.

3. Dichloromethane $\left(\mathrm{CH}_{2} \mathrm{Cl}_{2}\right), \geq 99.8 \%, \sim 20 \mathrm{ppm}$ amylene as stabilizer, water $\left(\mathrm{H}_{2} \mathrm{O}\right)<0.02 \%$.

4. Pyridine (Py), water $\left(\mathrm{H}_{2} \mathrm{O}\right)<0.01 \%$.

5. 5'-Aldehyde-Modifier C2 phosphoramidite and 2'-O-TBDMS-5, $N$-protected ribophosphoramidites only with the UltraMILD base-protecting groups (e.g., acetyl, phenoxyacetyl, 4-isopropyl-phenoxyacetyl). Phosphoramidite solutions prepared in AcN at concentration $0.1 \mathrm{M}$ are generally stable for up to 2 weeks when stored under inert atmosphere (see Notes 2, 3).

6. Solid support: $N$-Protected 5'-O-DMTr-2'-O-acetyl-nucleoside -3'-succinoyl-long chain alkylamino-CPG, $500 \AA$ A pore size, $\sim 24-35 \mu \mathrm{mol}$ loading. For the synthesis of 3'-aminocontaining oligonucleotide, use a special solid support as $N$-(6-(O-DMTr)-hexyl)-(2carboxamide)-phthalimidyl-lcaa-CPG.

7. Activator for coupling: $0.25 \mathrm{M}$ solution of 5-(ethylthio)-1H-tetrazole (ETT) in AcN (see Note 2).

8. Capping reagent A: THF/acetic anhydride/2,6-lutidine, 8/1/1, v/v/v.

9. Capping reagent B: THF/N-methylimidazole, $84 / 16$, v/v (see Note 2).

10. Oxidizing reagent: $0.02 \mathrm{M}$ solution of iodine in $\mathrm{THF} / \mathrm{H}_{2} \mathrm{O} / \mathrm{Py}, 45 / 4.5 / 0.5$, v/v/v. 
11. Detritylating reagent: $3 \%$ Dichloroacetic acid (DCA) (v/v) in $\mathrm{CH}_{2} \mathrm{Cl}_{2}$.

12. DNA/RNA synthesizer, corresponding columns and filters. We use ASM-800 (Biosset).

\subsection{Synthesis of oligoribonucleotides conjugated with cholesterol through hydrazone bond}

1. Acetic acid, $99-100 \%$.

2. Dioxane, $99.8 \%$.

3. NaOAc buffer (0.1 M, pH 5.2).

4. HEPES-NaOH buffer (0.1 M, pH 7.5).

5. HEPES-NaOH buffer (0.1 M, pH 8.5).

6. Fluorescein isothiocyanate isomer I.

7. N-succinimidyl ester of ATTO-565 (ATTO-TEC).

8. Dimethyl sulfoxide (DMSO), $\geq 99.5 \%$.

9. Ethanol, 94-96\%.

10. Cleavage reagent 1 (AMA solution): $40 \%$ methylamine in water/concentrated ammonium hydroxide solution, 1/1, v/v, freshly prepared. Concentrated (28-30\%) ammonium hydroxide solution store at $-20{ }^{\circ} \mathrm{C}$.

11. Cleavage reagent 2: $0.05 \mathrm{M} \mathrm{K}_{2} \mathrm{CO}_{3}$ in methanol.

12. Washing reagent: $\mathrm{AcN} / \mathrm{H}_{2} \mathrm{O} /$ ethanol, $1 / 1 / 1$, v/v/v.

13. Acetone, water $\left(\mathrm{H}_{2} \mathrm{O}\right)<0.2 \%$.

14. Solution for precipitation: $2 \%$ (w/v) $\mathrm{NaClO}_{4}(\geq 98.0 \%)$ solution in acetone.

15. 2'-O-TBDMS deprotecting cocktail: $N$-methylpyrrolidinone/triethylamine/triethylaminetris(hydrogen fluoride), 3/1.5/2, v/v/v, freshly prepared (see Note 4).

16. Ethoxytrimethylsilane, $98 \%$;

17. Diethyl ether (Sigma-Aldrich).

18. Speedvac Concentrator Plus.

19. Thermomixer Comfort. 
20. Centrifuge $5424 \mathrm{R}$.

\subsection{Analysis and purification of lipophilic RNAconjugates}

1. Ethanol, 94-96\%.

2. Acetone, water $\left(\mathrm{H}_{2} \mathrm{O}\right)<0.2 \%$.

3. $N, N, N, N^{\prime}$-Tetramethylethylenediamine (TEMED). Store at $4^{\circ} \mathrm{C}$.

4. TBE×10 Buffer: 0.5 M Tris-HCl, $\mathrm{pH} 8.3,0.5 \mathrm{M}$ boric acid, $10 \mathrm{mM}$ EDTA.

5. Ammonium persulfate (APS): $10 \%(\mathrm{w} / \mathrm{v})$ solution in water, freshly prepared (see Note 5).

6. Solution to prepare denaturing polyacrylamide gel for oligonucleotide isolation and analysis: $12 \%$ solution of acrylamide/ $N, N^{\prime}$-methylenebisacrylamide (30/0.5), $7 \mathrm{M}$ urea, TBE $\times 1$ Buffer (see Note 6).

7. Loading Buffer: $7 \mathrm{M}$ urea, $0.025 \%$ bromphenol blue, $0.025 \%$ xylene cyanol FF.

8. Stains-All: $0.05 \%(\mathrm{w} / \mathrm{v})$ solution in formamide/water, $1 / 1, \mathrm{v} / \mathrm{v}$.

9. Ethidium Bromide solution $(1 \mu \mathrm{g} / \mathrm{mL})$ in water; UV-transilluminator.

10. Elution buffer: $0.3 \mathrm{M} \mathrm{NaOAc}$ solution in water, $\mathrm{pH}$ 7.0. Store at $4{ }^{\circ} \mathrm{C}$.

11. Standard equipment for polyacrylamide gel electrophoresis.

12. Kieselgel F254 thin-layer chromatography plate covered with polyethylene or polypropylene film for visualizing oligonucleotides and their conjugates on gels by UV shadowing.

13. Thermomixer Comfort.

14. Speedvac Concentrator.

15. Spectrophotometer NanoDrop.

\subsection{Transfection of human cultured cells with lipophilic conjugates}

1. Cultured human cells: HepG2, HEK293T, 143B or human skin fibroblasts.

2. EMEM (Essential Modified Eagle's Medium) or MEM (Minimum Essential Medium Eagle) containing $1 \mathrm{mg} / \mathrm{mL}$ glucose.

3. OptiMEM, Reduced Serum medium for transfection. 
4. PBS, Dulbecco's phosphate buffered saline without $\mathrm{CaCl}_{2}$.

5. Streptomycin, penicillin, Fungizone, 100x solutions.

6. FBS, fetal bovine serum.

7. MitoTracker Deep Red (Molecular Probes) dissolved in dimethyl sulfoxide (DMSO) at 100 $\mu \mathrm{M}$ concentration, aliquoted and stored at $-20^{\circ} \mathrm{C}$.

\section{Methods}

Here we describe in details the chemical synthesis of the oligoribonucleotides conjugated with cholesterol residue through hydrazone bond.

For this, hydrazide of 6-(cholesteryloxycarbonylamino)hexanoic acid should be synthesized

(Fig. 2, Subheading 3.1) and then conjugated with 5'-O-Aldehyde-modified oligoribonucleotide. This reaction can be performed by conjugation "in solution" or on solid-phase (Figs. 3, 5).

\subsection{Synthesis of hydrazide of 6-(cholesteryloxycarbonylamino)hexanoic acid}

\subsubsection{6-(Cholesteryloxycarbonylamino)-hexanoic acid (compound 1 Fig. 2, step i) (22))}

Suspend 6-aminohexanoic acid $(0.9 \mathrm{~g}, 6.6 \mathrm{mmol})$ in dry pyridine $(15 \mathrm{ml})$, then add chlorotrimethylsilane $(3.3 \mathrm{ml}, 26.4 \mathrm{mmol})$ dropwise at $0^{\circ} \mathrm{C}$. Stir the mixture until the solution became clear, then add cholesteryl chloroformate $(1 \mathrm{~g}, 2.2 \mathrm{mmol})$ and stir the reaction mixture for $3 \mathrm{~h}$ at r.t. Evaporate pyridine under reduced pressure, dissolve the residue in $\mathrm{CH}_{2} \mathrm{Cl}_{2}(100 \mathrm{ml})$, wash with $0.7 \mathrm{M} \mathrm{HCl}(50 \mathrm{ml})$ followed by saturated aqueous $\mathrm{NaCl}(50 \mathrm{ml})$. Dry the organic phase under anhydrous $\mathrm{Na}_{2} \mathrm{SO}_{4}$ and evaporate under reduced pressure. Purify the residue by Silica gel column chromatography $\left(\mathrm{CH}_{2} \mathrm{Cl}_{2} / \mathrm{EtOH}, 0-30 \%\right)$ to obtain compound $\mathbf{1}$ with a yield 0.95 g (80\%). $\mathrm{H}^{1}$-NMR (400 MHz, $\mathrm{CDCl}_{3}, \delta$, ppm): 0.69 (s, 3H, H-18/19 cholesterol); 0.87 (d, 3H, H-26/27 cholesterol); 0.89 (d, 3H, H-26/27 cholesterol); 0.93 (d, 3H, H-21 cholesterol); 1.025 (s, 3H, H-18/19 cholesterol); 2.33 (t, 2H, $\left.-\underline{\mathrm{C}}_{2}-\mathrm{COOH}\right) ; 3.35$ (dd, $2 \mathrm{H},-\mathrm{C}_{2}-\mathrm{NH}-$ ); 4.51 (m, 1H, H-3 cholesterol); 4.88 (t, 1H, -NH-); 5.4 (d, 1H, H-6 cholesterol). 


\subsubsection{Methyl 6-(cholesteryloxycarbonylamino)hexanoate (compound 2 Fig. 2, step ii)}

Dissolve compound $1(0.2 \mathrm{~g}, 0.37 \mathrm{mmol})$ in dry $\mathrm{CH}_{2} \mathrm{Cl}_{2}(5 \mathrm{ml})$, add phosphorus trichloride (13 $\mu \mathrm{l}, 0.149 \mathrm{mmol}$ ) and stir the reaction mixture for $3 \mathrm{~h}$ under argon at $50{ }^{\circ} \mathrm{C}$. Add absolute methanol $(1 \mathrm{ml})$, dilute by $\mathrm{CH}_{2} \mathrm{Cl}_{2}(45 \mathrm{ml})$, wash with saturated aqueous $\mathrm{NaHCO}_{3}(50 \mathrm{ml})$ and twice with water $(50 \mathrm{ml})$. Dry the organic phase under anhydrous $\mathrm{Na}_{2} \mathrm{SO}_{4}$ and evaporate to oily residue. Purify the product 2 by Silica gel column chromatography $\left(\mathrm{CH}_{2} \mathrm{Cl}_{2} / \mathrm{EtOH}, 0-2.5 \%\right)$ (yield $0.165 \mathrm{~g}, 80 \%$ ). $\mathrm{H}^{1}$-NMR (400 MHz, $\mathrm{CDCl}_{3}, \delta$, ppm): 0.69 (s, 3H, H-18/19 cholesterol); 0.87 (d, 3H, H-26/27 cholesterol); 0.89 (d, 3H, H-26/27 cholesterol); 0.93 (d, 3H, H-21 cholesterol); 1.025 (s, 3H, H-18/19 cholesterol); 2.29 (t, 2H, $\left.-\mathrm{CH}_{2}-\mathrm{C}(\mathrm{O}) \mathrm{OCH}_{3}\right) ; 3.35$ (dd, $2 \mathrm{H},-$ $\left.\underline{\mathrm{C}}_{2}-\mathrm{NH}-\right)$; 3.65 (s, 3H, $\left.-\mathrm{CH}_{2}-\mathrm{C}(\mathrm{O}) \mathrm{OC} \underline{H}_{3}\right) ; 4.51$ (m, 1H, H-3 cholesterol); 4.88 (t, 1H, -NH-); 5.4 (d, 1H, H-6 cholesterol).

\subsubsection{Hydrazide of 6-(cholesteryloxycarbonylamino)hexanoic acid (compound 3 Fig. 2, step iii)}

Dissolve compound $2(0.1 \mathrm{~g}, 0.18 \mathrm{mmol})$ in methanol $(5 \mathrm{ml})$ (23). Add hydrazine monohydrate $(1.25 \mathrm{~mL}, 49 \mathrm{mmol})$ dropwise, and incubate the reaction mixture for $8 \mathrm{~h}$ at $\mathrm{r}$. t. Precipitate compound 3 in cold water $(100 \mathrm{ml})$, filter it off, wash with water and dry (yield $0.089 \mathrm{~g}, 89 \%$ ). $\mathrm{H}^{1}$-NMR (400 MHz, $\left.\mathrm{CDCl}_{3}, \delta, \mathrm{ppm}\right): 0.69$ (s, 3H, H-18/19 cholesterol); 0.87 (d, 3H, H-26/27 cholesterol); 0.89 (d, 3H, H-26/27 cholesterol); 0.93 (d, 3H, H-21 cholesterol); 1.025 (s, 3H, H18/19 cholesterol); 2.13 (t, $2 \mathrm{H},-\mathrm{CH}_{2}-\mathrm{C}(\mathrm{O}) \mathrm{NH}-\mathrm{NH}_{2}$ ); 3.35 (dd, $2 \mathrm{H},-\mathrm{C}_{2}-\mathrm{NH}-$ ); 3.85 (s, $2 \mathrm{H},-$

$\left.\mathrm{CH}_{2}-\mathrm{C}(\mathrm{O}) \mathrm{NH}-\mathrm{NH}_{2}\right) ; 4.51$ (m, 1H, H-3 cholesterol); 4.88 (t, 1H, -NH-); 5.4 (d, 1H, H-6 cholesterol); 6.75 (s, $\left.\mathrm{H},-\mathrm{CH}_{2}-\mathrm{C}(\mathrm{O}) \mathrm{N} \underline{\mathrm{H}}-\mathrm{NH}_{2}\right)$.

\subsection{Automated phosphoramidite synthesis of oligoribonucleotides and their aldehyde- modified analogs}

Here we provide detailed protocol for the oligonucleotide synthesis on an automatic DNA/RNA synthesizer ASM-800 at $0.4 \mu \mathrm{mol}$ scale using the solid phase phosphoramidite technique (see 
Notes $2,3,7$ ). Synthesis of any oligonucleotide is carrying according to the synthesizer's program. The steps of each cycle: detritylation, coupling, capping and oxidation with appropriate washings (steps 2-10).

1. Pack 10-15 mg of required solid support in the appropriate column, place on the automated ASM-800 synthesizer and wash with AcN $(280 \mu 1)$ during $15 \mathrm{~s}$.

2. Wash with $\mathrm{CH}_{2} \mathrm{Cl}_{2}(190 \mu \mathrm{l}) 12 \mathrm{~s}$.

3. Detritylation: remove 5'-O-dimethoxytrityl group from the first support-bound nucleoside during $120 \mathrm{~s}$ with detritylating reagent $(350 \mu \mathrm{l})$.

4. Wash with AcN (300 $\mu$ l) during $15 \mathrm{~s}$.

5. Coupling: add a mixture (1/1, v/v) of phosphoramidite monomer solution and 0.25 M ETT (140 $\mu \mathrm{l}$ ) for $10 \mathrm{~min}$ (for 2'-O-TBDMS-protected RNA phosphoramidites).

6. Wash with AcN $(100 \mu l)$ during 5 s.

7. Capping: add a mixture of capping reagents A and B (1/1, v/v) $(240 \mu \mathrm{l})$ during $30 \mathrm{~s}$ for capping of unreacted 5'-hydroxyl groups of oligonucleotides.

8. Wash with AcN $(100 \mu \mathrm{l})$ during $10 \mathrm{~s}$.

9. Oxidation: oxidize the phosphite-triester to phosphorotriester with oxidizing reagent $(160 \mu \mathrm{l})$ during $65 \mathrm{~s}$.

10. Wash with AcN $(400 \mu \mathrm{l})$ during $30 \mathrm{~s}$.

11. Carry as many cycles as necessary for the synthesis of oligoribonucleotide.

12. Repeat steps 2-10 using 5'-Aldehyde-Modifier C2 phosphoramidite to introduce protected aldehyde function at the 5'-end of oligonucleotide chain (see Note 8).

13. Wash the column with AcN and dry thoroughly.

\subsection{Solid-phase synthesis of oligoribonucleotides conjugated with cholesterol through hydrazone bond}

3.3.1. Conjugation of 5'-aldehyde-modified polymer-bound protected RNAs with hydrazide of 6(cholesteryloxycarbonylamino)hexanoic acid (Fig. 3) 
1. Transfer fully protected 5'-aldehyde-modified CPG-bound RNA (10-15 mg, 0.24-0.35 $\mu$ mol, Subheading 3.2) from the synthesis column to a $0.6 \mathrm{~mL}$ tube and incubate with $80 \%$ acetic acid (400 $\mu \mathrm{l}) 1 \mathrm{~h}$ at r.t. to remove the acetal protecting group.

2. Wash polymer-bound RNA with water $(3 \times 200 \mu \mathrm{l}), \mathrm{AcN}(2 \times 200 \mu \mathrm{l})$ and acetone $(2 \times 200 \mu \mathrm{l})$ and dry thoroughly.

3. Dissolve hydrazide of 6-(cholesteryloxycarbonylamino)hexanoic acid (3) (1.9 mg, $3.5 \mu \mathrm{mol})$ in dioxane $(50 \mu \mathrm{l})$, mix with the same volume of $0.1 \mathrm{M} \mathrm{NaOAc}$ pH 5.2 and add to the 5'aldehyde-containing CPG-bound protected RNA.

4. Carry out the reaction $16 \mathrm{~h}$ at r.t. with stirring.

5. Wash the support-bound conjugate with dioxane $(3 \times 200 \mu 1)$, AcN $(2 \times 200 \mu 1)$, acetone $(2 \times 200$ $\mu 1)$ to remove an uncoupled lipophilic compound, and then dry.

\subsubsection{Cleavage of lipophilic conjugates of RNAs from the support and removal of base-labile} and 2'-O-TBDMS protecting groups

1. Transfer solid support with lipophilic conjugates of RNAs to a new $0.6 \mathrm{~mL}$ tube.

2. Add $0.05 \mathrm{M} \mathrm{K}_{2} \mathrm{CO}_{3}$ in methanol $(400 \mu \mathrm{L})$ and incubate at r.t. for $16 \mathrm{~h}$ with shaking (see Note 9). Use the microtube cap locks (Thomas Scientific) to avoid the loss of material.

3. Transfer the soluble material to $1.5-\mathrm{mL}$ tube, wash the solid support with $\mathrm{AcN} / \mathrm{H}_{2} \mathrm{O} /$ ethanol $(1 / 1 / 1 \mathrm{v} / \mathrm{v} / \mathrm{v})(150 \mu \mathrm{L})$ twice, combine all the solutions, neutralize with acetic acid $(2 \mu \mathrm{L})($ see Note 10) and evaporate in a Speedvac up to final volume $100 \mu \mathrm{L}$ (see Note 11). Precipitate by addition of ten volumes $2 \% \mathrm{NaClO}_{4}$ in acetone $(1 \mathrm{~mL})$ to obtain the dry pellet.

4. Add the freshly prepared and preheated to $65^{\circ} \mathrm{C} 2$ '-O-TBDMS deprotecting cocktail $(200 \mu \mathrm{L})$ to the pellet and incubate the reaction mixture at $65{ }^{\circ} \mathrm{C}$ for 90 min with shaking (see Note 4). 5. To quench the reaction, add ethoxytrimethylsilane $(300 \mu \mathrm{L})$ and mix well. Be careful, it is important to hold the tube cap and open it slightly to avoid loss of material because during this step abundant gas evolution occurs. Incubate the crude reaction mixture for 10 min at r.t., add 
diethyl ether $(1 \mathrm{~mL})$ to precipitate oligonucleotide, and then incubate the tube for $10 \mathrm{~min}$ at -20 ${ }^{\circ} \mathrm{C}$ and centrifuge for $3 \mathrm{~min}$ at $14000 \mathrm{~g}$.

6. Remove the supernatant, rinse the pellet with acetone and air dry until the smell of organic solvents disappears (do not dry off the oligoribonucleotide pellet), dissolve the dry pellet in 100 $\mu \mathrm{L}$ of $50 \mathrm{mM}$ HEPES-NaOH buffer $\mathrm{pH} 7.5$ (see Note 12).

\subsubsection{Analysis and purification of crude lipophilic conjugates of RNAs}

1. Measure the amount of crude lipophilic conjugates by NanoDrop spectrophotometer.

2. Check crude modified lipophilic conjugates of RNAs by analytical electrophoresis in $12 \%$ denaturing polyacrylamide gel. About $\sim 0.05-0.1 \mathrm{OD}_{260}(\sim 1-2 \mu \mathrm{g})$ of oligonucleotide can be loaded per $0.5 \mathrm{~cm}$ width well, visualize the bands by Stains-all or Ethidium Bromide staining (Fig. 4, see Notes 6, 13).

3. For gel-purification, load $10-15 \mathrm{OD}_{260}$ of the synthesized lipophilic conjugates mixed with an equal volume of the Loading buffer per the $5 \mathrm{~cm}$ width well.

4. After migration at 5-10 V/cm, detect the band of the lipophilic conjugates of RNA by a UVshadowing method (254 nm irradiation), cut from gel and elute by shaking in $600-1000 \mu \mathrm{L}$ of 0.3M NaOAc (pH 7.0) for $16 \mathrm{~h}$ at $25^{\circ} \mathrm{C}$.

5. Take the supernatant, add four volumes of ethanol, and incubate for $4-16 \mathrm{~h}$ at $-20{ }^{\circ} \mathrm{C}$.

6. After centrifugation, wash the pellet twice with chilled $80 \%$ ethanol (until no acetic acid smell), and dry in a SpeedVac for 1 minute. Dissolve the pellet in $100 \mu \mathrm{L}$ of $50 \mathrm{mM}$ HEPES$\mathrm{NaOH}$ buffer $\mathrm{pH} 7.5$ (see Note 12), measure the amount and check the purity of lipophilic conjugates of RNAs by analytical electrophoresis as detailed above (steps 1, 2) (see Note 13).

7. Presence of cleavable hydrazone bond can be assayed by incubation of an aliquot of the conjugate in acidic conditions (see Note 10). For this, mix $10 \mu \mathrm{L}(1 \mu \mathrm{g})$ of purified conjugate (step 6) and $40 \mu \mathrm{L}$ acetic acid, incubate at $37{ }^{\circ} \mathrm{C}$ for $10 \mathrm{~min}$, precipitate with ten volumes of $2 \%$ 
$\mathrm{NaClO}_{4}$ in acetone, dry the pellet on air until the smell of acetone disappears, dissolve in $50 \mathrm{mM}$ HEPES-NaOH buffer pH 7.5 and load on 12\% polyacrylamide-urea gel (Fig. 4, lane 5).

\subsection{Synthesis "in solution" of oligoribonucleotides and their fluorophore labelled derivatives conjugated with cholesterol through hydrazone bond}

3.4.1. Cleavage of aldehyde-modified RNAs from the support and removal of base-labile and 2'O-TBDMS protecting groups (Fig. 5)

1. Transfer fully protected 5'-aldehyde-modified CPG-bound RNA from the synthesis column to a $0.6 \mathrm{~mL}$ tube.

2. Add freshly prepared AMA solution $(400 \mu \mathrm{L}$, Subheading 2.3$)$ and incubate at $65^{\circ} \mathrm{C}$ for 15 min with shaking. Use the microtube cap locks (e.g. Thomas Scientific) or the tubes with screw caps to prevent the opening the tube.

3. Cool the tube at $4{ }^{\circ} \mathrm{C}$ for $15 \mathrm{~min}$ before opening.

4. Transfer the soluble material to $1.5-\mathrm{mL}$ tube, wash the solid support with $\mathrm{AcN} / \mathrm{H}_{2} \mathrm{O} / \mathrm{ethanol}$ $(150 \mu \mathrm{L})$ twice, combine all the solutions and evaporate in a Speedvac to obtain the dry pellet.

5. Remove of 2'-O-TBDMS protecting groups (Subheading 3.3.2, steps 4-6).

6. Analyze the quality of the oligoribonucleotide by electrophoresis in a $12 \%$ polyacrylamideurea gel and purify if necessary (Subheading 3.3.3).

3.4.2. Conjugation of 5'-aldehyde-containing RNAs with hydrazide of 6(cholesteryloxycarbonylamino)hexanoic acid "in solution"

1. Incubate RNA containing protected aldehyde function (5 units $\mathrm{A}_{260}$ ) with $80 \%$ acetic acid $1 \mathrm{~h}$ at r.t. to remove the acetal protecting group.

2. Add ten volumes of $2 \% \mathrm{NaClO}_{4}$ in acetone; mix well and centrifuge $3 \mathrm{~min}$ at $14000 \mathrm{~g}$.

3. Remove supernatant, rinse the pellet with acetone and dry the pellet on air until the smell of acetone disappears. 
4. Re-dissolve the pellet of 5'-aldehyde-containing RNA in $0.1 \mathrm{M} \mathrm{NaOAc} \mathrm{pH} 5.2(50 \mu \mathrm{L})$ (see

\section{Note 12).}

5. Dissolve hydrazide of 6-(cholesteryloxycarbonylamino)hexanoic acid (3) (3 mg, $5.2 \mathrm{mmol}$ ) in dioxane $(50 \mu \mathrm{l})$ and mix with the solution of 5'-aldehyde-containing RNA.

6. Carry out the reaction $12 \mathrm{~h}$ at r.t. with permanent stirring. Precipitate the oligonucleotide material by adding ten volumes of $2 \% \mathrm{NaClO}_{4}$ in acetone/diethyl ether $(1 / 1 \mathrm{v} / \mathrm{v})$, keep $15 \mathrm{~min}$ at $-20^{\circ} \mathrm{C}$ and centrifuge $10 \mathrm{~min}$ at $16000 \mathrm{~g}, 4^{\circ} \mathrm{C}$. Remove supernatant, rinse the pellet with acetone and dry the pellet on air until the smell of organic solvents disappears.

7. Analyze the quality of the lipophilic conjugate by electrophoresis in a $12 \%$ polyacrylamideurea gel (Subheading 3.3.3).

\subsubsection{Synthesis of fluorophore labelled conjugates}

For labelling of lipophilic conjugates with fluorophores, the conjugate should contain 3 '-terminal aminolinker (Fig. 6). For the synthesis of 3'-amino-containing oligonucleotide, use special amino-containing solid support as $N$-(6-( $O$-DMTr)-hexyl)-(2-carboxamide)-phthalimidyl-lcaaCPG.

1. Add ten volumes of $2 \% \mathrm{NaClO}_{4}$ in acetone to the solution of $3^{\prime}$-amino-containing lipophilic conjugate (1 unit $\mathrm{A}_{260}$, Subheading 3.4.2), mix well, incubate at $-20^{\circ} \mathrm{C}$ for $15 \mathrm{~min}$ and centrifuge $10 \mathrm{~min}$ at $16000 \mathrm{~g}$.

2. Remove the supernatant; wash the pellet with acetone and dry.

3. For labelling with FITC (see Note 14), dissolve the pellet in $30 \mu \mathrm{L}$ of $0.1 \mathrm{M}$ HEPES-NaOH (pH 8.5) (see Note 12). Add FITC solution (0.3 mg in $30 \mu$ DMSO) and mix well. Use black tubes, avoid the bright light during all the manipulations with the fluorescent dyes and labelled RNA. 
4. For labelling with ATTO-565 (see Note 14), dissolve the pellet (step 2) in $85 \mu \mathrm{L}$ of $0.1 \mathrm{M}$ HEPES-NaOH (pH 8.5) and mix with $15 \mu \mathrm{L}$ of $N$-succinimidyl ester of ATTO-565 in dry DMSO (5 mg/ml). Use black tubes.

5. Carry out the reaction with FITC or ATTO-565 overnight at $25^{\circ}$ with permanent stirring (800 rpm).

6. Precipitate the conjugate by adding four volumes of ethanol; incubate $4 \mathrm{~h}$ at $-20{ }^{\circ} \mathrm{C}$.

7. After centrifugation at $16000 \mathrm{~g}$ for $10 \mathrm{~min}$, remove the supernatant; wash the pellet with chilled ethanol and air dry (in the dark) until the smell of ethanol disappears. Dissolve the pellet in $100 \mu \mathrm{L}$ of $50 \mathrm{mM}$ HEPES-NaOH buffer $\mathrm{pH}$ 7.5.

8. Remove the non-incorporated fluorescent dye by Bio-Spin columns P6 or P30 (Bio-Rad).

9. To check the efficiency of the labelling, compare the fluorescent dye absorbance and the oligonucleotide nitrous bases absorbance (260 nm) using NanoDrop Microarray Program (24).

\subsection{Transfection of cultured human cells with lipophilic conjugates}

To detect and quantify the cellular uptake of RNA conjugated with cholesterol, cultured human cells incubated with fluorescently labelled conjugates can be analyzed by flow cytometry and/or fluorescent confocal microscopy.

1. Grow the cells in $2 \mathrm{~cm}^{2}$ wells in EMEM or MEM medium supplemented with $10 \% \mathrm{FBS}$, penicillin, streptomycin, and fungizone in a $\mathrm{CO}_{2}$ incubator (at $37{ }^{\circ} \mathrm{C}, 5 \% \mathrm{CO}_{2}$ ) to the confluence of $70 \%$.

2. Dilute purified fluorescently labelled conjugates in OptiMEM to final concentration 70-200 $\mathrm{nM}$ (see Note 15).

3. Wash the cells with phosphate-buffered saline (PBS), add $500 \mu 1 /$ well of OptiMEM containing conjugates. Incubate cells overnight $(15 \mathrm{~h})$ at $37{ }^{\circ} \mathrm{C}, 5 \% \mathrm{CO}_{2}$, keeping them in the dark.

4. Remove the transfection mixture and add $0.5 \mathrm{ml}$ of EMEM medium for $1 \mathrm{~h}$ to eliminate noninternalized oligonucleotides from the cells surface. 
5. Wash the cells twice with PBS, detach, centrifuge at $600 \mathrm{~g}$ for $10 \mathrm{~min}$, resuspend the pellet of cells in ice-cold PBS. Keep the cells protected from direct light.

6. Perform flow cytometry analysis to estimate the percentage of fluo-positive cells in the population (normally $~ 90 \%$, see Note 16). We use CyFlow ${ }^{\circledR}$ Space (Partec), equipped with a $488 \mathrm{~nm}$ laser and a $592 \mathrm{~nm}$ bandpass filter for detecting the cells internalized ATTO-565 labelled conjugates (Fig. 7A).

7. For fluorescent confocal microscopy, grow the cells in $0.5 \mathrm{~mL}$ of EMEM on chambered coverglass for microscopy with 4 wells $\left(2 \mathrm{~cm}^{2}\right.$ ) (Lab-Tek) to the confluence of $60-80 \%$.

8. Transfect cells with fluorescently labelled conjugates as described above (steps 2-3).

9. Replace the medium with $0.5 \mathrm{~mL}$ of DMEM containing MitoTracker Deep Red (or other MitoTracker dye) at final concentration $100 \mathrm{nM}$, incubate for $15 \mathrm{~min}$ in a $\mathrm{CO}_{2}$ incubator at $37^{\circ} \mathrm{C}$. 10. Aspirate medium and wash cells gently 3 times with PBS, add $1 \mathrm{~mL}$ of DMEM without red phenol. Perform cell imaging using a confocal laser scanning microscope (Fig. 7B). We use the LSM 700 confocal scanning microscope (Zeiss LSM 700) in conjunction with Zen imaging software and a Zeiss 40x/1.30 oil immersion objective.

\section{Notes}

1. Organic solvents and chemicals should be of high quality (Sigma-Aldrich, Acros, Merck), and stored in a dark place. For personal protection, use a lab coat, safety glasses, and gloves. Work with all chemicals in a well-ventilated chemical hood.

2. You may use phosphoramidites, reagents and solvents from different manufacturers (Glen Research, ChemGen, Sigma-Aldrich, TriLink, etc.). To improve the quality and yield of the oligonucleotide synthesis, remove the trace amounts of moisture by adding molecular sieves (3 $\AA$ A, 8 to 12 mesh) to phosphoramidite solutions, activator solution, capping reagent $\mathrm{B}$, and acetonitrile. 
3. All steps of chemical synthesis should be handled under the inert atmosphere. We use helium gas for operating ASM-800 DNA/RNA synthesizer, for the other synthesizers use gas recommended by the manufacturer.

4. Use the $2^{\prime}-O$-TBDMS deprotecting cocktail only freshly prepared and hot $\left(65^{\circ} \mathrm{C}\right)$.

5. The APS solution can be stored at $4{ }^{\circ} \mathrm{C}$ for no more than one week. Longer storage can affect the acrylamide polymerization and the quality of oligonucleotide separation.

6. To separate the oligoribonucleotides and their lipophilic conjugates (Fig. 4), we use polyacrylamide gels with a small proportion of the $N, N^{\prime}$-methylenebisacrylamide linker (30/0.5). The stock solution must be prepared from the individual components supplied in powder form (toxic by inhalation, please use a mask!). Commercial stock solution acrylamide/ $N, N^{\prime}-$ methylenebisacrylamide (37.5/1) can also be used. Solution of $12 \%$ acrylamide with $7 \mathrm{M}$ urea can be stored at $4^{\circ} \mathrm{C}$ for no more than three weeks.

7. You may synthesize oligonucleotides using other automatic DNA/RNA synthesizers (for example, from Applied Biosystems or Mermade) and protocols optimized for these instruments. To prevent the nuclease degradation of oligoribonucleotides and their analogs and conjugates, use only fresh ultrapure water (for example, by Simplicity® Water Purification System, Millipore, $18 \mathrm{M} \Omega-\mathrm{cm}$ at $25^{\circ} \mathrm{C}$ ) and sterile or autoclaved plastic tubes and tips; wear gloves when handling RNA samples; store all oligonucleotides and their conjugates at $-20{ }^{\circ} \mathrm{C}$.

8. Normally, the program of automatic DNA/RNA synthesizer includes the function of the final detritylation. This step must be canceled; otherwise, the acetal protection of the aldehyde group can be partially removed, which will lead to undesirable modification at the step of AMA (cleavage reagent 1, Subheading 3.4.1) treatment.

9. Cleavage reagent $2\left(0.05 \mathrm{M} \mathrm{K}_{2} \mathrm{CO}_{3}\right.$ in methanol) is not suitable for the cleavage of oligonucleotides synthesized on the amino-containing solid support.

10. To avoid cleavage of the hydrazone bond, it is necessary to carefully control the $\mathrm{pH}$ of all solutions. We tested the lability of the hydrazone link and demonstrated that it was stable at $\mathrm{pH}$ 
$>6.6$, while at $\mathrm{pH}<6.0$, the cholesterol residue was quickly split from the oligoribonucleotide (19). Since RNA molecules degrade at $\mathrm{pH}>8.8$, there is an interval of $6.8<\mathrm{pH}<8.5$ which must be respected to avoid the cleavage of conjugated molecules.

11. At this step, avoid complete evaporation of the solution as this may lead to the degradation of the conjugated oligoribonucleotide.

12. Be careful when handling the tube with a dry pellet of oligonucleotide conjugate. Centrifuge the tube before opening and open it very carefully; otherwise, the pellet can fly out of the tube upon opening.

13. Samples of crude lipophilic conjugates obtained after cleavage from the support and removal of protecting groups (Subheading 3.3.2) contain, besides lipophilic conjugates (Fig. 4, lane 2, upper band), also non-conjugated oligoribonucleotides (lower band) and the products of incomplete synthesis visible as a smear. Therefore, before labeling the lipophilic conjugates with fluorophores and/or transfection of human cells, the conjugated molecules should be gel-purified (Subheading 3.3.3). Unfortunately, the efficiency of elution of the conjugates from the gel is rather low. We have tested various elution techniques, and the best one (Subheading 3.3.3) offers only a yield of around $50 \%$.

14. For the choice of a fluorescent dye, we should take into account two characteristics: the charge of the fluorescent dye and its possible interaction with lipid bilayers (membrane interaction factor, MIF). Positively charged fluorophores can induce a nonspecific accumulation of the oligoribonucleotide on the mitochondrial surface (25), providing the false positive results of mitochondrial targeting. The interaction of fluorescent dye with lipid bilayer (26) can lead to an important decrease of the labelled RNA import into mitochondria. Here we provide protocols for two dyes, Fluorescein isothiocyanate (FITC, green fluorescence) and ATTO-565 (red fluorescence). Fluorophore labelling can affect the cellular accumulation and biological activity of RNA conjugates, as it was recently demonstrated for siRNA (27). Noteworthy, our blot hybridization experiments also demonstrated that unlabelled RNA molecules were more 
efficiently imported into mammalian mitochondria compared to fluorescently labelled RNAs (not shown).

15. Oligoribonucleotide components of conjugated molecules can be rapidly degraded by nucleases, which are present in FBS (fetal bovine serum). The RNA molecules incubated in culture media supplemented with FBS are quickly degraded (28). Therefore, the carrier-free cell transfection with lipophilic oligoribonucleotide conjugates should be performed in a medium with reduced serum content (such as OptiMem). Cells grown in complete medium should be washed before transfection (Subheading 3.5) to remove traces of FBS.

16. The efficiency of cell transfection was evaluated with a gel-purified fluorescently labelled conjugate (19). When using the crude reaction mixture, it is important to estimate the proportion of lipophilic conjugate compared to unconjugated oligoribonucleotide (Fig. 4, see also Note 13).

\section{Acknowledgements}

The authors thank the Center of Chemical Investigations of N.N.Vorozhtsov, Novosibirsk Institute of Organic Chemistry SB RAS for NMR analysis.

This work was funded by Strasbourg University, RFBR and CNRS (joint project PRC CNRS/RFBR mito TARN 20-54-15005), French National Research Agency (ANR) through the Programme d'Investissement d'Avenir under contract ANR-17-EURE-0023 and Labex MitoCross, and partly supported by the Russian State-funded budget project of ICBFM SB RAS \# AAAA-A17-117020210021-7.

\section{Figure Captions}

Figure 1. The strategy of the carrier-free cell delivery (adapted from (11)). A, Biodegradable conjugate of the importable RNA (shown by a helix) with cholesterol (in pink) can be internalized by endocytosis in a non-toxic and formulation-free manner; then RNA is released in late endosomes due to the change of $\mathrm{pH}$ and can be partially targeted into mitochondria. $\mathbf{B}$, 
Structure of the lipophilic conjugate of RNA. In blue, anti-replicative RNA; in pink, cholesterol residue: in green, $\mathrm{pH}$-dependent hydrazone bond.

Figure 2. Scheme of the chemical synthesis of hydrazide of 6-(cholesteryloxycarbonyl amino)hexanoic acid. Reagents: i) $\left(\mathrm{CH}_{3}\right)_{3} \mathrm{SiCl}, \mathrm{Py}, 4{ }^{\circ} \mathrm{C}$; CholOC(O)Cl, Py, r.t.; $\mathrm{H}_{3} \mathrm{O}^{+} ;$ii $) \mathrm{PCl}_{3}$, $\mathrm{CH}_{2} \mathrm{Cl}_{2}$, argon, $50{ }^{\circ} \mathrm{C} ; \mathrm{MeOH}_{\text {abs }}$, r.t.; iii) $\mathrm{NH}_{2} \mathrm{NH}_{2} \mathrm{H}_{2} \mathrm{O}, \mathrm{MeOH}$, r.t. (from (19) with modifications).

Figure 3. Scheme of the solid-phase synthesis of oligoribonucleotides (OLIGO) conjugated with cholesterol (R-) through covalent hydrazone bond.

Figure 4. PAGE separation of the following compounds: lane 1, oligoribonucleotide containing 5'-aldehyde group (ON); lane 2, an aliquot of reaction mixture for synthesis of lipophilic conjugate (Subheading 3.3.2); lanes 3-4, lipophilic conjugates purified by PAGE (Chol ON); lane 5, gel-purified lipophilic conjugate incubated under acidic conditions to partially cleave the hydrazone bond.

Figure 5. Scheme of the synthesis "in solution" of lipophilic conjugates containing hydrazone bond.

Figure 6. Labelling of lipophilic conjugates with fluorophore dyes.

Figure 7. Evaluation of the cellular uptake of lipophilic conjugates. A, An example of flow cytometry analysis, cells were incubated $15 \mathrm{~h}$ with $70 \mathrm{nM}$ ATTO-565 labelled conjugate. In gray, signal corresponding to auto-fluorescence of non-transfected cells. B, Confocal microscopy images of human skin fibroblasts transfected with $70 \mathrm{nM}$ ATTO-565 labelled conjugate (upper panel, yellow signal), $26 \mathrm{~h}$ post-transfection; lower panel represents control non-transfected cells. Mitochondrial network was visualized by MitoTracker DeepRed staining. The excitation/emission laser wavelengths were 555/585 nm (yellow channel) and 639/660 nm (red magenta channel). 


\section{References}

1. Jeandard D, Smirnova A, Tarassov I, Barrey E, Smirnov A, Entelis N (2019) Import of Non-

Coding RNAs into Human Mitochondria: A Critical Review and Emerging Approaches. Cells 8 (3). doi:10.3390/cells8030286

2. Wallace DC (2010) Mitochondrial DNA mutations in disease and aging. Environ Mol Mutagen $51(5): 440-450$

3. Kolesnikova O, Kazakova H, Comte C, Steinberg S, Kamenski P, Martin RP, Tarassov I, Entelis N (2010) Selection of RNA aptamers imported into yeast and human mitochondria. Rna 16 (5):926-941. doi:10.1261/rna.1914110

4. Tonin Y, Heckel AM, Vysokikh M, Dovydenko I, Meschaninova M, Rotig A, Munnich A, Venyaminova A, Tarassov I, Entelis N (2014) Modeling of antigenomic therapy of mitochondrial diseases by mitochondrially addressed RNA targeting a pathogenic point mutation in mitochondrial DNA. J Biol Chem 289 (19):13323-13334. doi:10.1074/jbc.M113.528968

5. Loutre R, Heckel AM, Jeandard D, Tarassov I, Entelis N (2018) Anti-replicative recombinant 5S rRNA molecules can modulate the mtDNA heteroplasmy in a glucose-dependent manner. PloS one 13 (6):e0199258. doi:10.1371/journal.pone.0199258

6. Comte C, Tonin Y, Heckel-Mager AM, Boucheham A, Smirnov A, Aure K, Lombes A, Martin RP, Entelis N, Tarassov I (2013) Mitochondrial targeting of recombinant RNAs modulates the level of a heteroplasmic mutation in human mitochondrial DNA associated with Kearns Sayre Syndrome. Nucleic Acids Res 41 (1):418-433. doi:10.1093/nar/gks965

7. Loutre R, Heckel AM, Smirnova A, Entelis N, Tarassov I (2018) Can Mitochondrial DNA be CRISPRized: Pro and Contra. IUBMB life. doi:10.1002/iub.1919

8. Zhou J, Rossi JJ (2011) Cell-specific aptamer-mediated targeted drug delivery.

Oligonucleotides 21 (1):1-10. doi:10.1089/oli.2010.0264

9. Ni R, Feng R, Chau Y (2019) Synthetic Approaches for Nucleic Acid Delivery: Choosing the Right Carriers. Life 9 (3). doi:10.3390/life9030059 
10. Zhou X, Wang S, Zhu Y, Pan Y, Zhang L, Yang Z (2019) Overcoming the delivery barrier of oligonucleotide drugs and enhancing nucleoside drug efficiency: The use of nucleolipids. Medicinal research reviews. doi:10.1002/med.21652

11. Dovydenko I, Venyaminova A, Pyshnyj D, Tarassov I, Entelis N (2016) Modifications in therapeutic oligonucleotides improving the delivery. In: Jurga S, Erdmann VA, Barciszewski J (eds) Modified Nucleic Acids in Biology and Medicine. Springer, Swizerland, pp 319-337. doi:10.1007/978-3-319-34175-0_14

12. Craig K, Abrams M, Amiji M (2018) Recent preclinical and clinical advances in oligonucleotide conjugates. Expert opinion on drug delivery 15 (6):629-640. doi:10.1080/17425247.2018.1473375

13. De Haes W, Van Mol G, Merlin C, De Smedt SC, Vanham G, Rejman J (2012) Internalization of mRNA lipoplexes by dendritic cells. Mol Pharm 9 (10):2942-2949 14. Durymanov M, Reineke J (2018) Non-viral Delivery of Nucleic Acids: Insight Into Mechanisms of Overcoming Intracellular Barriers. Frontiers in pharmacology 9:971. doi:10.3389/fphar.2018.00971

15. Singh Y, Murat P, Defrancq E (2010) Recent developments in oligonucleotide conjugation. Chemical Society reviews 39 (6):2054-2070. doi:10.1039/b911431a

16. Benizri S, Gissot A, Martin A, Vialet B, Grinstaff MW, Barthelemy P (2019) Bioconjugated Oligonucleotides: Recent Developments and Therapeutic Applications. Bioconjug Chem 30 (2):366-383. doi:10.1021/acs.bioconjchem.8b00761

17. Stanislawska I, Liwinska W, Lyp M, Stojek Z, Zabost E (2019) Recent Advances in Degradable Hybrids of Biomolecules and NGs for Targeted Delivery. Molecules 24 (10). doi:10.3390/molecules24101873

18. Meschaninova MI, Novopashina DS, Semikolenova OA, Silnikov VN, Venyaminova AG (2019) Novel Convenient Approach to the Solid-Phase Synthesis of Oligonucleotide Conjugates. Molecules 24 (23). doi:10.3390/molecules24234266 
19. Dovydenko I, Tarassov I, Venyaminova A, Entelis N (2016) Method of carrier-free delivery of therapeutic RNA importable into human mitochondria: Lipophilic conjugates with cleavable bonds. Biomaterials 76:408-417. doi:10.1016/j.biomaterials.2015.10.075

20. Meschaninova M, Entelis N, Chernolovskaya E, Venyaminova A (2020) A versatile approach to the synthesis of oligonucleotide conjugates with biodegradable hydrazone linkers. Org Biomol Chem in press

21. West KR, Otto S (2005) Reversible covalent chemistry in drug delivery. Current drug discovery technologies 2 (3):123-160. doi:10.2174/1570163054866882

22. Yamada C, Khvorova A, Kaiser R, Anderson E, Leake D (2013) Duplex oligonucleotide complexes and methods for gene silencing by RNA interference.

23. Tognolini M, Incerti M, Hassan-Mohamed I, Giorgio C, Russo S, Bruni R, Lelli B, Bracci L, Noberini R, Pasquale EB, Barocelli E, Vicini P, Mor M, Lodola A (2012) Structure-activity relationships and mechanism of action of Eph-ephrin antagonists: interaction of cholanic acid with the EphA2 receptor. ChemMedChem 7 (6):1071-1083. doi:10.1002/cmdc.201200102 24. Dovydenko I, Heckel AM, Tonin Y, Gowher A, Venyaminova A, Tarassov I, Entelis N (2015) Mitochondrial targeting of recombinant RNA. Methods Mol Biol 1265:209-225. doi:10.1007/978-1-4939-2288-8_16

25. Rhee WJ, Bao G (2010) Slow non-specific accumulation of 2'-deoxy and 2'-O-methyl oligonucleotide probes at mitochondria in live cells. Nucleic Acids Res 38 (9):e109 26. Hughes LD, Rawle RJ, Boxer SG (2014) Choose your label wisely: water-soluble fluorophores often interact with lipid bilayers. PloS one 9 (2):e87649

27. Chernikov IV, Gladkikh DV, Meschaninova MI, Karelina UA, Ven'yaminova AG, Zenkova MA, Vlassov VV, Chernolovskaya EL (2019) Fluorophore Labeling Affects the Cellular Accumulation and Gene Silencing Activity of Cholesterol-Modified siRNAs In Vitro. Nucleic acid therapeutics 29 (1):33-43. doi:10.1089/nat.2018.0745 
28. Volkov AA, Kruglova NS, Meschaninova MI, Venyaminova AG, Zenkova MA, Vlassov VV, Chernolovskaya EL (2009) Selective protection of nuclease-sensitive sites in siRNA prolongs silencing effect. Oligonucleotides 19 (2):191-202 

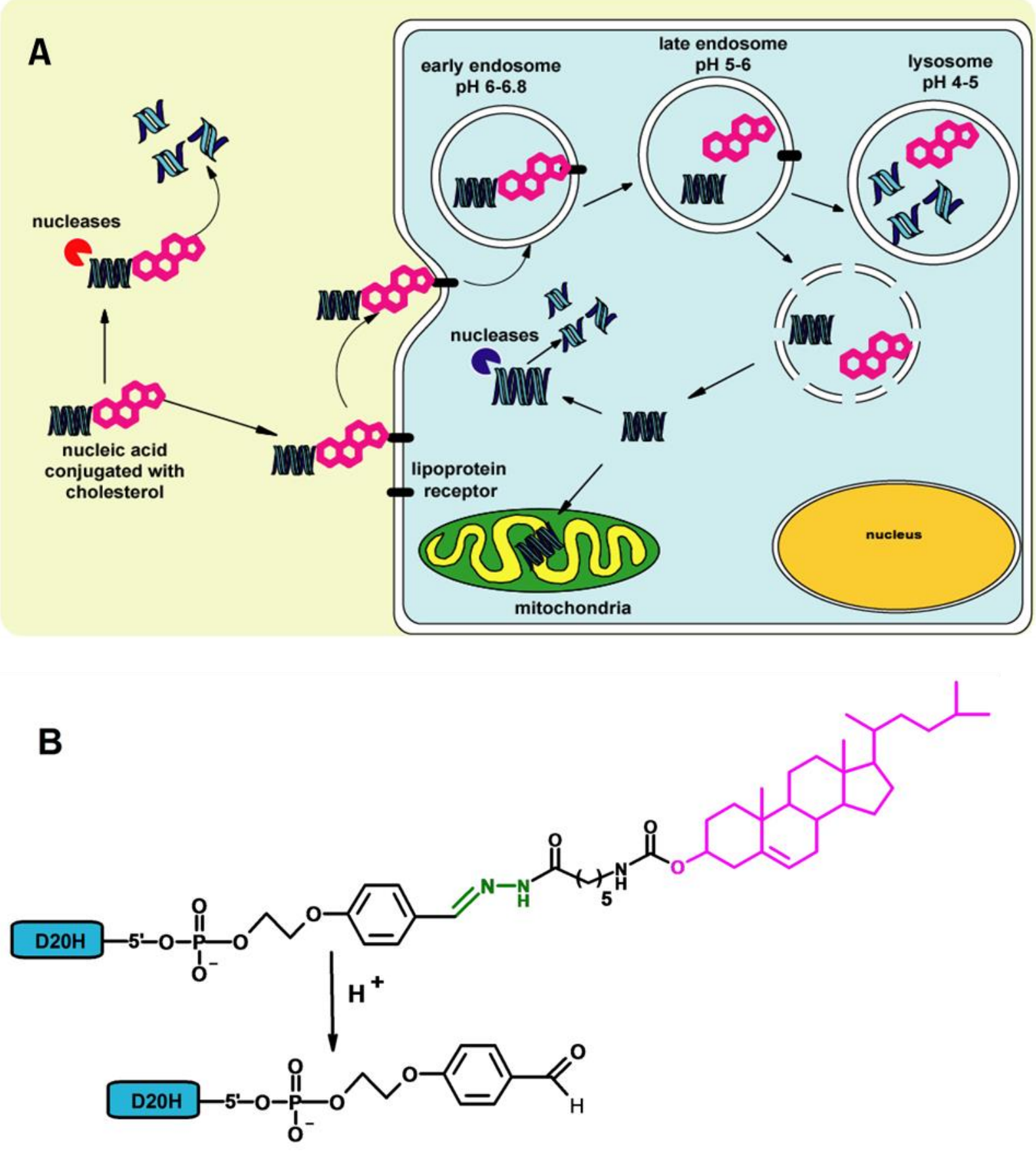

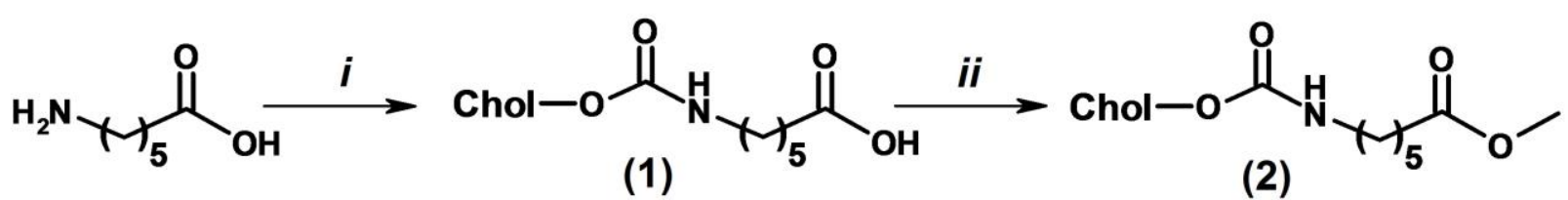<smiles>CC#CCOOC(=O)NC(C)C(=O)NN</smiles>

Chol-O- :<smiles>COC1CCC2(C)C(=CCC3C2CCC2(C)C(C(C)CCC(C)C)CCC32)C1</smiles> 


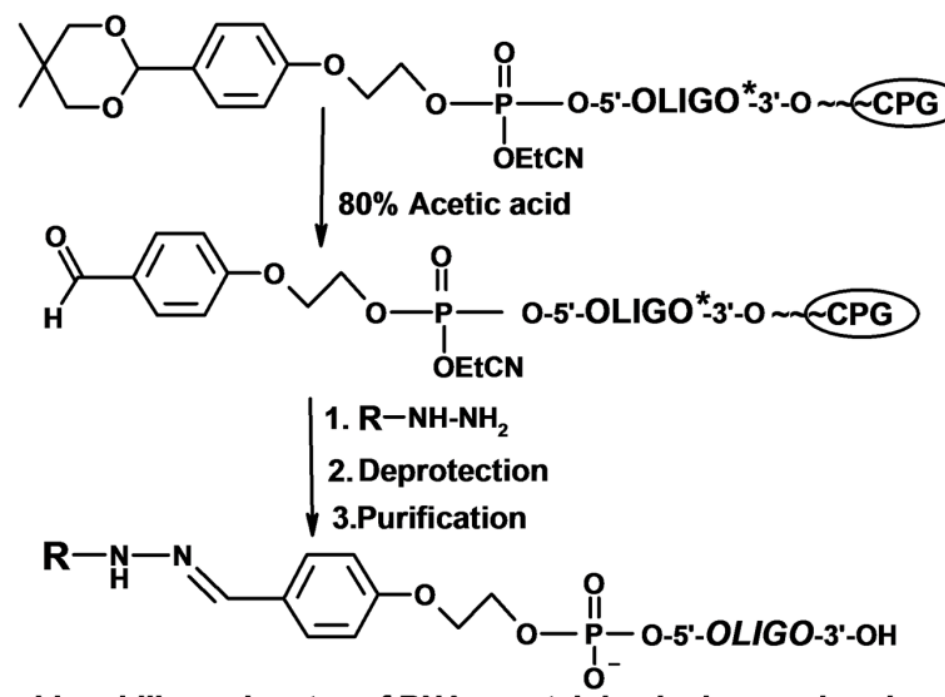

Lipophilic conjugates of RNAs containing hydrazone bond

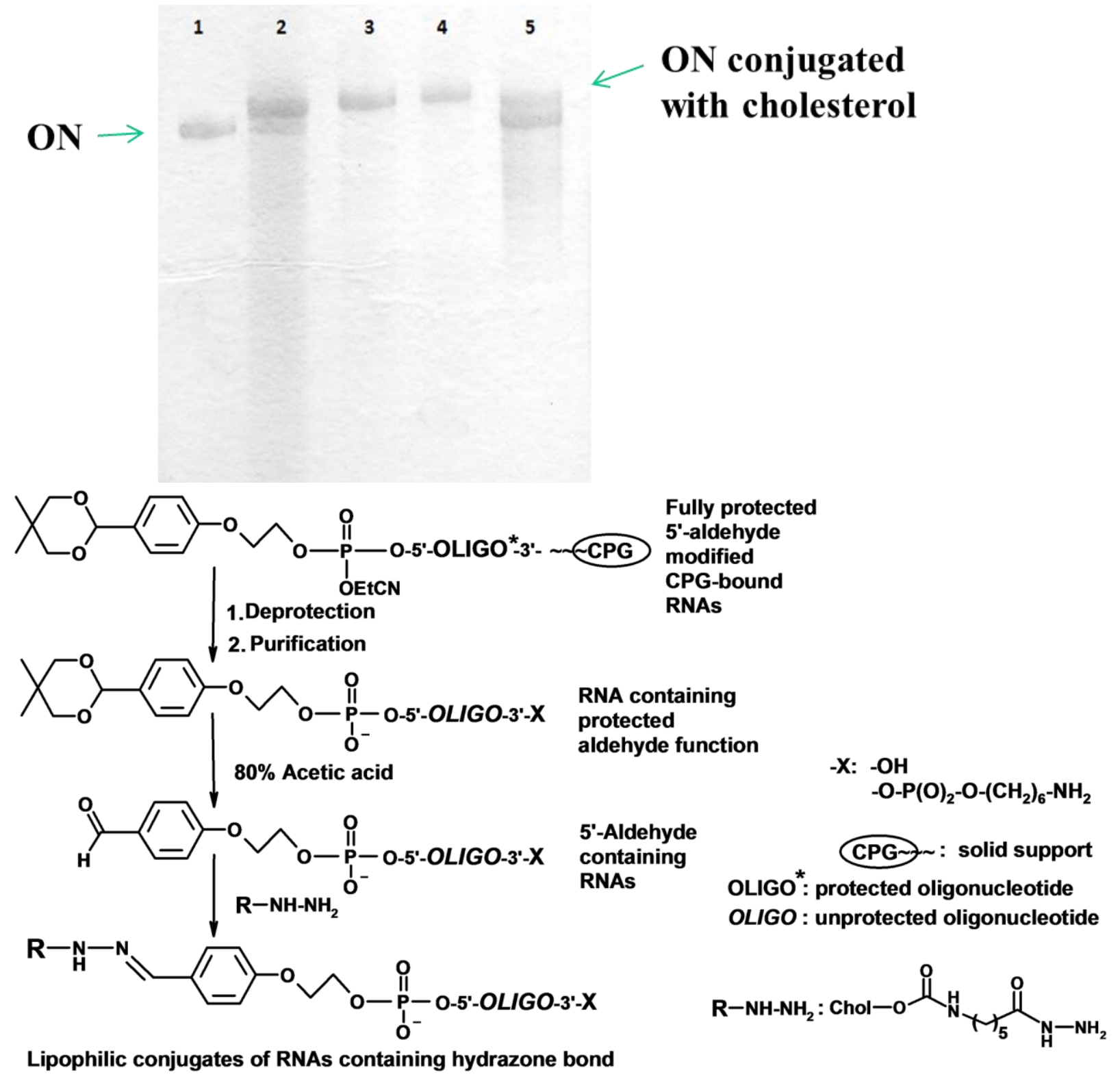

Fully protected

modified

RNAs

5'-Aldehyde

containing

CPG-bound

protected

RNAs CPG : solid support OLIGO*: protected oligonucleotide OLIGO : unprotected oligonucleotide<smiles>[R]NNC=COOC(=O)NC(C)C(=O)NN</smiles>

5'-aldehyde

CPG-bound 

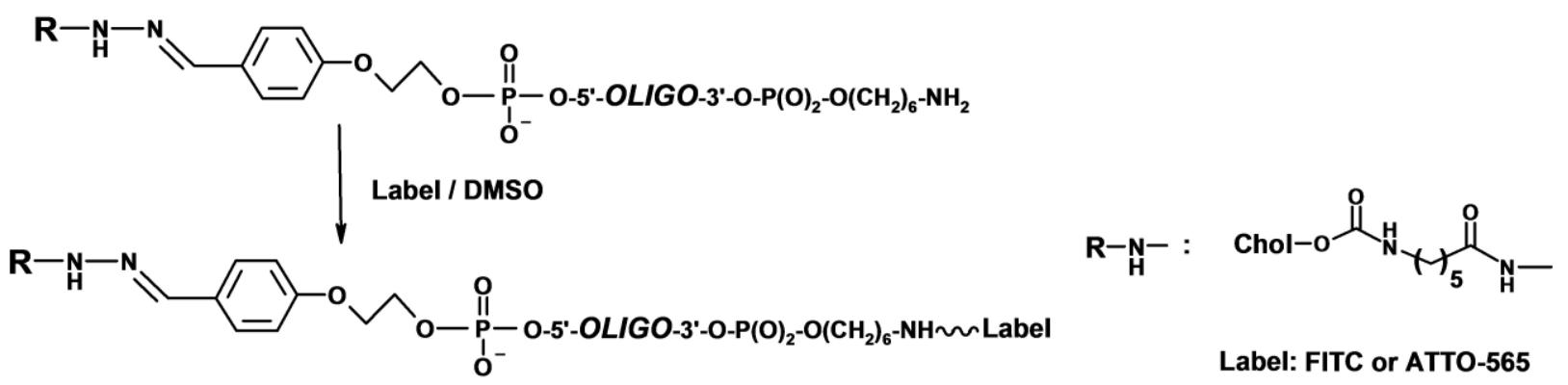
Label: FITC or ATTO-565

Labelled conjugates of RNAs

OLIGO : unprotected oligonucleotide

A

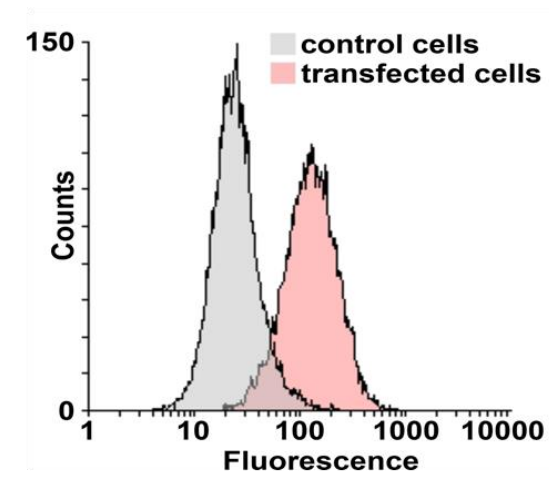

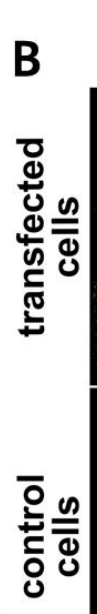

MitoTracker

Deep Red
Merge 